\title{
Shifts of archaeal community structure in soil along an elevation gradient in a reservoir water level fluctuation zone
}

\author{
Fei Ye ${ }^{1,2} \cdot$ Shengjun $\mathrm{Wu}^{1} \cdot$ Yi Jiang ${ }^{1} \cdot$ Huub J. M. Op den Camp ${ }^{3} \cdot \mathrm{Zhe}^{\mathrm{Li}^{1}}{ }^{1}$ \\ Guibing $\mathrm{Zhu}^{4}$. Jun Zheng ${ }^{5}$ Y Yu Wang ${ }^{1}$ (D)
}

Received: 22 February 2016 / Accepted: 13 June 2016 / Published online: 20 June 2016

(C) Springer-Verlag Berlin Heidelberg 2016

\begin{abstract}
Purpose Although archaea play an important role in nutrients cycling, the archaeal community in a reservoir water-level fluctuation zone (WLFZ) remains unclear. An elucidation of archaeal community responding to the environmental variables is essential to understand the nutrients dynamics in WLFZ. This study focused on the response of the archaeal community structure and abundance to the periodic water flooding along an elevation gradient in the WLFZ of the Three Gorges Reservoir.

Materials and methods Along the elevation gradient (152$175 \mathrm{~m}$ ) of the study area, soil samples in the beginning and late stages of water flooding were collected to investigate the influence of water flooding on the archaeal community in soil, using quantitative PCR and Illumina high-throughput sequencing approaches.
\end{abstract}

Responsible editor: Jizheng $\mathrm{He}$

Electronic supplementary material The online version of this article (doi:10.1007/s11368-016-1485-3) contains supplementary material, which is available to authorized users.

Yu Wang

wangyu@ cigit.ac.cn

1 Chongqing Institute of Green and Intelligent Technology, Chinese Academy of Sciences, Chongqing 400714, China

2 University of Chinese Academy of Sciences, Beijing 100049, China

3 Department of Microbiology, IWWR, Radboud University Nijmegen, Nijmegen 6525 AJ, The Netherlands

4 Key Laboratory of Drinking Water Science and Technology, Research Center for Eco-Environmental Sciences, Chinese Academy of Sciences, Beijing 100085, China

5 China-ASEAN Environmental Cooperation Center, Ministry of Environmental Protection of China, Beijing 100035, China
Results and discussion An increase of archaeal abundance from $3.8 \times 10^{8}$ to $3.8 \times 10^{9}$ copies $(\mathrm{g} \mathrm{d} \text {.w.s })^{-1}$ on average was observed after water flooding. The archaeal abundance was positively correlated with the contents of ammonium, organic matter, and moisture in soil and with the accumulated flooding time. Higher diversity was observed in dry samples (non-flooded soil samples) rather than wet samples (flooded soil samples). The Thaumarchaeota were predominant in most of the dry samples. Interestingly, high proportions of Candidatus Nitrososphaera were observed in the transition zone, while euryarchaeotal methanogens dominated the wet samples. The proportion of methanogens decreased dramatically in the dry samples at higher elevations, which was associated with the decrease of the moisture content and the probably increase of available oxygen in soil.

Conclusions Archaeal abundance, diversity, and community composition shifted along an elevation gradient and were influenced by water flooding. The increased archaea abundance after water flooding and elevation related community composition and diversity indicated that water flooding was a key dynamic environmental variable in the WLFZ.

Keywords Archaeal community $\cdot$ High-throughput sequencing · Quantitative PCR · Three Gorges Reservoir · Water flooding $\cdot$ Water level fluctuation zone

\section{Introduction}

Archaea, constituting the third fundamental domain of life, were perceived mainly as a group of microorganisms thriving in extreme habitats until 1990s (Offre et al. 2013). The discoveries of archaea in oceanic plankton (Delong 1992; Fuhrman et al. 1992) have triggered a huge number of follow-up studies showing that archaea represented an 
abundant and diverse group of microorganisms in the whole biosphere (Leininger et al. 2006; Wuchter et al. 2006; Bates et al. 2011; Pester et al. 2011; Offre et al. 2013). A significant impact of archaea on nutrient cycling was realized than previously expected (Offre et al. 2013; Reitschuler et al. 2016). In carbon cycling, methane produced by methanogenic archaea accounted for $70 \%$ of the global methane emission (Whitman et al. 2006). The lithoautotrophic archaea was shown to oxidize $\mathrm{NH}_{3}$ to $\mathrm{NO}_{2}^{-}$(Könneke et al. 2005), and their high numbers in nature suggested a prominent role in global nitrogen cycling (Leininger et al. 2006; Wuchter et al. 2006). Additionally, archaea actively involved in sulfur cycling by rapidly converting $\mathrm{CS}_{2}$ into $\mathrm{H}_{2} \mathrm{~S}$ and $\mathrm{CO}_{2}$ (Smeulders et al. 2011).

The distribution of archaeal assemblages was affected by both biotic and abiotic factors along ecological gradients (Braker et al. 2001; Angel et al. 2010; Liu et al. 2014). Many environmental factors were able to shape the archaeal community, such as altitude (Zhang et al. 2009), salinity (Jin et al. 2011), redox potential (DeAngelis et al. 2010), and pH (Tripathi et al. 2013). Water regime was observed to be predominant on the archaeal community over regional and seasonal variations, and over the differences between individual habitats in soil (Høj et al. 2006). Therefore, the fluctuating water level was probably of great significance in regulating the archaeal community and related nutrients cycling (Antheunisse et al. 2007) in riparian zone.

The Three Gorges Dam (TGD) in China is the world's largest hydroelectric project (Yuan et al. 2012; Xu et al. 2013). The Three Gorges Reservoir (TGR)-triggered ecological issues draw wide attention globally (Stone 2008; Qiu 2009) and make the dam one of the most controversial hydraulic projects in China (Xu et al. 2013; Bao et al. 2015). Many of these issues pertain to the reservoir's riparian zone, which is also referred to as the water-level fluctuation zone (WLFZ) (Bao et al. 2015). The water level rises to the highest level of $175 \mathrm{~m}$ in winter and drops to $145 \mathrm{~m}$ in summer, which is reverse to the fluctuation of natural water bodies (Fig. 1) (China Three Gorges Corporation 2015).

The nutrients dynamics in the zone were investigated in the last few years (Chen et al. 2010; Ye et al. 2012; Ye et al. 2015). However, the microbial background remained largely unclear. In light of the substantial roles of archaea in nutrients cycling, an elucidation of the archaeal



Fig. 1 Maps of the Three Gorges Reservoir showed the location of the sampling area (orange star) and respective landscape in summer and winter 
community is essential for the understanding of the nutrients dynamics in reservoir's WLFZ. Furthermore, such a study would also be helpful to evaluate the ecological influence of reservoir projects potentially, considering the large and increasing amount of reservoirs in China (more than 98,000 with capacity $>100,000 \mathrm{~m}^{3}$ per reservoir) (Sun et al. 2013). Additionally, the WLFZ (TGR) is characterized by the anti-seasonal inundation rhythm and prolonged flooding duration, which make the WLFZ a unique and ideal ecosystem to show the response of archaea to alternating wet and dry conditions.

In the present study, we focused on the archaeal community structure in the WLFZ of the TGR and analyzed the influence of dynamic environmental variables on the archaeal abundance, community structure, and diversity. Illumina highthroughput sequencing and quantitative PCR (qPCR) approaches were employed. Environmental parameters of soil samples were investigated. Statistical analyses of Pearson correlation, one-way ANOVA, and principal component analysis were conducted to reveal the links between the archaeal community structure and abundance and the environmental parameters.

\section{Materials and methods}

\subsection{Site description and sampling}

The sampling area of Baijiaxi is located in the Pengxi River Wetland Reserve $\left(34^{\circ} 54^{\prime} \mathrm{N}\right.$ to $34^{\circ} 24^{\prime} \mathrm{N}, 108^{\circ} 28^{\prime} \mathrm{E}$ to $108^{\circ} 33^{\prime}$ E). The Pengxi River is one of the most important primary tributaries of the TGR. The study area is a typical WLFZ with the same rhythms of water level fluctuations as the TGR and nearly the full range of inundation (152-175 m) (Fig. 1). The water level keeps rising from about September to November every year and maintained at a high level until about April of the following year.
In order to investigate the influence of water flooding on the soil microbial community, samples were taken in the beginning and late stages of water flooding, which was at 10 October 2013 and 1 April 2014 with water level of 168.6 and $160.2 \mathrm{~m}$, respectively. Along the elevation gradient of the study area, two dry samples (unflooded soil samples) and four wet samples (flooded soil samples) were collected on 10 October 2013. At the late stage (1 April 2014), four dry samples and three wet samples were collected (Table 1). The soil textures were mainly silt clay, excepting the lowest elevation sample in 2013 of which the soil texture was silt sandy. The sample ID of 175-2013, for example, represented a sample collected at $175 \mathrm{~m}$ elevation in 10 October 2013. The sample 1522013 was excluded for further analysis due to the obvious difference of soil texture. Among those, the samples of 165-2013, 170-2013, 160-2014, and 161-2014 near the water level (168.6 and $160.2 \mathrm{~m})$ were regarded as the transition samples, which were used to investigate the influence of short-term flooding to archaea. Surface soil samples $(0-10 \mathrm{~cm})$ were collected using a stainless steel soil core sampler or a Petersen grab (wet samples at lower elevations), and three adjacent sub-samples were collected at each site to form a composite sample. Each collected composite sample was divided into two subsamples. One was stored at $4{ }^{\circ} \mathrm{C}$ for the physicochemical analysis, and the other one was stored at $-20{ }^{\circ} \mathrm{C}$ for DNA extraction and molecular analysis. Eight samples represented all eight possible flooding statuses were chosen for Illumina high-throughput sequencing, which were the samples of the longest flooding time (155-2013 and 152-2014), the shortest flooding time (175-2013 and 175-2014), and recently flooded (165-2013), soon to be flooded (1702013), exposed recently (161-2014), and soon to be exposed (160-2014). The accumulated flooding time (AFT) in each site was the flooding duration (days) from the day of the lowest water level in 2013 to the sampling time.

Table 1 Information of samples and sampling sites

\begin{tabular}{lllll}
\hline Sampling time & Sample IDs & Sample type & Soil texture & Sampling elevation (m) \\
\hline 2013.10 .11 & $175-2013$ & Dry sample & Silt clay & 175 \\
& $170-2013$ & Dry sample & Silt clay & 170 \\
& $165-2013$ & Wet sample & Silt clay & 165 \\
$160-2013$ & Wet sample & Silt clay & 160 \\
2014.04 .01 & Wet sample & Silt clay & 155 \\
& $155-2013$ & Wet sample & Silt sandy & 152 \\
& $152-2013^{\text {a }}$ & Dry sample & Silt clay & 175 \\
& $175-2014$ & Dry sample & Silt clay & 170 \\
$170-2014$ & Dry sample & Silt clay & 165 \\
& $165-2014$ & Silt clay & 161 \\
& $161-2014$ & Silt clay & 160 \\
& $160-2014$ & Wet sample & Silt clay & 155 \\
& $155-2014$ & Wet sample & Silt clay & 152 \\
\hline
\end{tabular}

${ }^{a}$ Sample was excluded for further analysis due to the different soil texture 


\subsection{Analytical procedures of physicochemical properties}

The $\mathrm{pH}$ was measured after shaking with water at a soil/water ratio of 1:5 and moisture was measured gravimetrically. The ammonium $\left(\mathrm{NH}_{4}{ }^{+}\right)$and nitrate $\left(\mathrm{NO}_{3}{ }^{-}\right)$were determined by flow injection analysis (FOSS Tecator, Sweden) after extracting with $2 \mathrm{M} \mathrm{KCl}$ solution. The total carbon (TC), total nitrogen (TN), and total sulfur (TS) were measured by an Element Analyser (Elementar, Germany). The organic matter $(\mathrm{OM})$ was measured through $\mathrm{LOI}_{550}$ (Loss on ignition at $550^{\circ} \mathrm{C}$ ) (Zhou et al. 2014). Ferrous iron $\left(\mathrm{Fe}^{2+}\right)$ and ferric iron $\left(\mathrm{Fe}^{3+}\right)$ were measured colorimetrically using o-phenanthroline (Bao 2000). The $\mathrm{Fe}^{2+} / \mathrm{Fe}^{3+}$ ratio was employed as an indicator of the redox potential in the soil (Guodong et al. 2001). All these analyses were carried out in triplicate.

\subsection{DNA extraction and quantitative PCR}

DNA from soil sample was extracted according to the manufacturer's instruction using the PowerSoil DNA Isolation Kit (Mobio, USA). The DNA concentration was determined using a NanoVue Plus Spectrophotometer (GE Healthcare, UK) and the DNA quality was checked by $1 \%$ (weight/volume) agarose gel electrophoresis. The extracted DNA was stored at $-20{ }^{\circ} \mathrm{C}$ until use for qPCR and Illumina highthroughput sequencing.

The relative abundance of archaeal 16S rRNA gene was measured by qPCR using the archaea-specific primer pairs A364aF (5'-CGGGGYGCASCAGGCGCGAA-3') (Burggraf et al. 1997) and A934bR (5'-GTGCTCCCCCGCCAATTCCT-3') (Gro et al. 1998). The 16S rRNA gene of archaea was quantified against a standard curve using a 10 -fold serial dilution of plasmids containing archaeal $16 \mathrm{~S}$ rRNA gene fragments. The $20-\mu \mathrm{L}$ reaction mixtures contained $10 \mu \mathrm{L}$ SYBR $®$ Premix Ex Taq ${ }^{\mathrm{TM}}$ II (Takara, Japan), $0.8 \mu \mathrm{L}\left(10 \mathrm{pmol} \mu \mathrm{L}^{-1}\right)$ of both forward primer $\mathrm{A} 364 \mathrm{aF}$ and reverse primer A934bR, $1 \mu \mathrm{L}$ DMSO, $6.4 \mu \mathrm{L}$ sterilized water, and $1 \mu \mathrm{L}$ template DNA (ca. $1 \mathrm{ng}$ ). Quantitative PCR assay was performed in a Mastercycler (Eppendorf, Germany) using an initial denaturation at $95{ }^{\circ} \mathrm{C}$ for $2 \mathrm{~min}$, followed by 40 cycles of $20 \mathrm{~s}$ at $95^{\circ} \mathrm{C}, 60 \mathrm{~s}$ at $63{ }^{\circ} \mathrm{C}$, and $60 \mathrm{~s}$ at $68{ }^{\circ} \mathrm{C}$. The specificity of each amplicon was checked by melting-curve analysis. The efficiencies of qPCR were 77$85 \%\left(R^{2}>0.997\right)$. All qPCRs were run in triplicate with the DNA extracted from each soil samples.

\subsection{Amplification and high-throughput sequencing}

The V3-V5 region of the archaeal 16S rRNA gene (Wemheuer et al. 2012) was amplified by PCR using primers Arch344F (5'-barcode-ACGGGGYGCAGCAGGCGCGA-3') and Arch915R (5'-GTGCTCCCCCGCCAATTCCT-3'), in which the barcode is an eight-base sequence unique to each sample. The amplification was carried out using an ABI GeneAmp®
9700 with the following program: $95^{\circ} \mathrm{C}$ for $3 \mathrm{~min}$, then $32 \mathrm{cy}$ cles of $95{ }^{\circ} \mathrm{C}$ for $30 \mathrm{~s}, 55^{\circ} \mathrm{C}$ for $30 \mathrm{~s}$, and $72{ }^{\circ} \mathrm{C}$ for $45 \mathrm{~s}$, followed by a final extension at $72{ }^{\circ} \mathrm{C}$ for $10 \mathrm{~min}$. The PCR products were purified using an AxyPrep DNA Gel Extraction Kit (Axygen, USA). Prior to sequencing, the quantification of each PCR product was measured by a QuantiFluor ${ }^{\mathrm{TM}}$-ST blue fluorescence quantitative system (Promega, USA). Subsequently, purified amplicons were pooled in equimolar and paired-end $(\mathrm{PE})$ sequenced $(2 \times 300)$ on an Illumina MiSeq PE300 platform at Majorbio Bio-Pharm Technology Co., Ltd., Shanghai, China (http://www.Majorbio.com).

\subsection{Data analysis}

Raw fastq files were demultiplexed and quality-filtered using Trimmomatic (version 0.30 ). The 300 -bp reads were truncated at any site receiving an average quality score $<20$ over a 50 -bp sliding window, discarding the truncated reads that were shorter than $50 \mathrm{bp}$. According to overlap relationship between PE reads, paired reads were assembled into single sequences with overlaps of at least $10 \mathrm{bp}$. Two nucleotide mismatches in primer matching and reads containing ambiguous characters were removed. Reads that could not be assembled were discarded. Operational taxonomic units (OTUs) were defined with an identity threshold of $97 \%$ using UPARSE pipeline (vsesion 7.1, http://drive5.com/uparse/). Subsequently, rarefaction curve and Shannon index curve were carried out using Mothur (version v.1.30.1). Taxa were assigned using SILVA rRNA database (Release 119 http://www.arbsilva.de). Pearson's correlations and one-way ANOVA analyses were performed using IBM SPSS Statistics 19.0. Program R (version 3.0.1) was used to create principal component analysis (PCA) based on the Euclidean distance. Software of HemI (Heatmap Illustrator, version 1.0) was used to create a heat map plot based on the average linkage clustering (calculated distance between two clusters) and the Euclidean distance (calculated distance between two sets) (Deng et al. 2014a). Redundancy analyses (RDA) with 999 Monte Carlo permutation tests were conducted with CANOCO for Windows Version 4.5 using log-transformed data to evaluate the relationship between community composition and environmental variables. Graphs were generated using ORIGIN 8.0 software.

\subsection{Sequence accession numbers}

The raw data of high-throughput sequencing were deposited in NCBI Sequence Read Archive (SRA, http:/trace.nvbi.nlm. nih.gov/Traces/sra/sra.cgi) under accession number SRX1162829. 


\section{Results}

\subsection{Physicochemical properties}

The contents of $\mathrm{NH}_{4}{ }^{+}$and $\mathrm{OM}$ in soil samples were $4.92 \mathrm{mg} \mathrm{kg}^{-1}$ and $3.46 \%$ on average at the beginning of water flooding in 2013 (Fig. S1, Electronic Supplementary Material). Subsequently, these values increased to $6.38 \mathrm{mg} \mathrm{kg}^{-1}$ and $4.92 \%$ at the late stage in 2014 . For the contents of $\mathrm{NO}_{3}{ }^{-}, \mathrm{TN}, \mathrm{TC}$, and TS, decreases were observed during the flooding period. The $\mathrm{NO}_{3}^{-}$was $2.48 \mathrm{mg} \mathrm{kg}^{-1}$ in 2013 and decreased to $1.53 \mathrm{mg} \mathrm{kg}^{-1}$ after water flooding. The $\mathrm{TN}, \mathrm{TC}$, and TS which were $0.08,0.77$, and $0.02 \%$ on average decreased in 2014 to $0.05,0.65$, and $0.01 \%$, respectively. The ratio of $\mathrm{Fe}^{2+}$ to $\mathrm{Fe}^{3+}$ of dry samples in 2013 was 10.0 times higher on average than those obtained after water flooding in 2014. However, the ratio of wet samples in 2013 was one fifth of that in 2014 after water flooding. Therefore, the $\mathrm{Fe}^{2+} / \mathrm{Fe}^{3+}$ decreased in dry samples and increased in wet samples after water flooding. The $\mathrm{pH}$ values were also affected by water flooding; average $\mathrm{pH}$ of wet samples was 7.8 and 7.6 in 2013 and 2014 versus 6.7 and 7.0 for dry samples.

\subsection{Abundance of archaea}

The abundance of archaea before water flooding in 2013 ranged from $2.1 \times 10^{7}$ to $9.8 \times 10^{8}$ copies (g d.w.s.) ${ }^{-1}$ (d.w.s., dry weight soil). The abundance varied from $5.0 \times 10^{8}$ to $8.9 \times 10^{9}$ copies (g d.w.s.) ${ }^{-1}$ after flooding in 2014 , which was generally higher than those in the beginning stage
(Fig. 2). Archaeal abundance of wet samples was $4.7 \times 10^{8}$ and $7.3 \times 10^{9}$ copies (g d.w.s.) ${ }^{-1}$ on average in 2013 and 2014 , which were higher than those of dry samples $\left(2.2 \times 10^{8} \text { and } 1.1 \times 10^{9} \text { copies (g d.w.s. }\right)^{-1}$ in 2013 and 2014, respectively). Notably, the abundance of archaea in wet samples (152-2014, 155-2014, and 160-2014) after water flooding was significantly higher than the rest except for the transition sample (161-2014).

Correlation analysis was conducted to evaluate the links between the archaeal abundance and environmental variables in the WLFZ. Among the environmental variables, the $\mathrm{NH}_{4}{ }^{+}$ $(r=0.635, P<0.01), \mathrm{OM}(r=0.865, P<0.01)$, moisture content $(r=0.724, P<0.01)$, and AFT $(r=0.833, P<0.01)$ showed a significant correlation with the archaeal abundance (Table 2).

\subsection{Archaeal diversity and richness}

After the amplification of archaeal 16S rRNA genes, 8 samples (155-2013, 165-2013, 170-2013, and 175-2013 and 1522014, 160-2014, 161-2014, and 175-2014) were sequenced through the high-throughput sequencing (Table 3), and 452,692 trimmed sequences were retrieved with 50,370 59,814 sequences per sample $($ mean $=56,587)$. The read lengths ranged from 463 to $532 \mathrm{bp}$, with an average of $522 \mathrm{bp}$. Based on $97 \%$ similarity, 1801 OTUs were obtained with an average of 403 OTUs per sample.

The archaeal diversity of each sample reached the plateau at where the sequencing depth was far less than the sequences per sample (Fig. S2, Electronic Supplementary Material). The

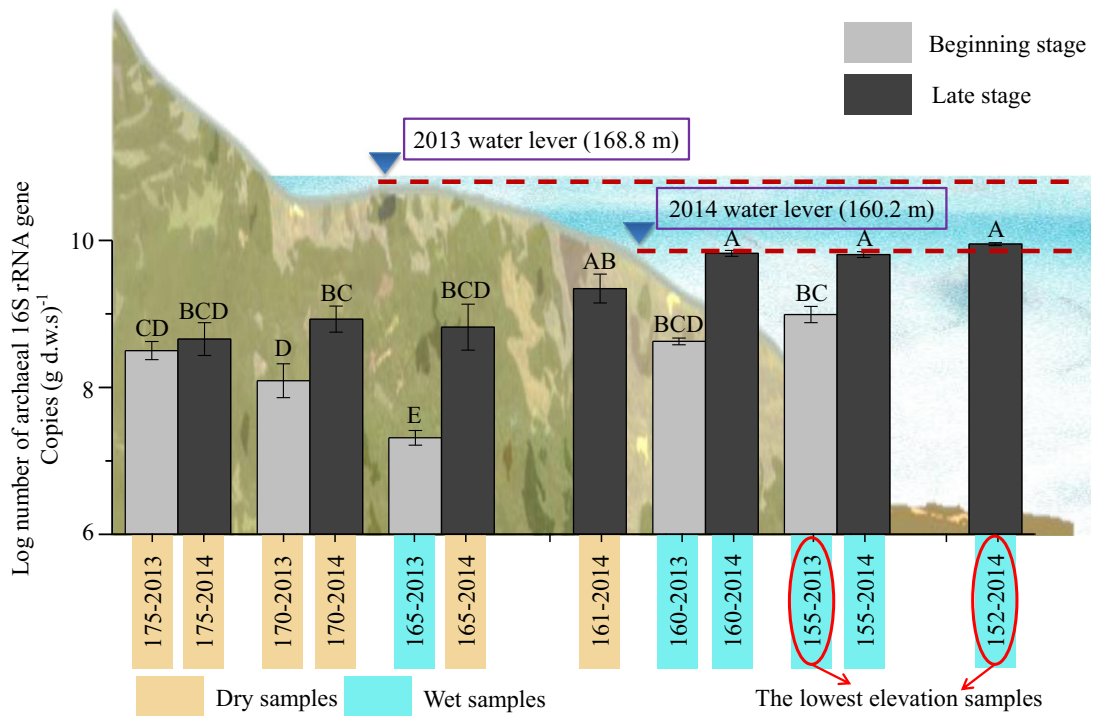

Fig. 2 The abundance of archaeal 16S rRNA genes at different elevations in 2013 and 2014. Sampling year and elevation were indicated in the name of sample. Light yellow and light blue indicated the samples in dry or wet conditions, respectively. Gray and black indicated the samples were collected in the beginning or later stage of water flooding, respectively. Samples 155-2013 and 152-2014 as the lowest elevation samples were circled in red. No sample was collected at the elevation of $161 \mathrm{~m}$ in 2013. Error bars indicated the standard deviation $(n=3)$. Different letters above the columns denoted a significant difference at $P<0.01$ 
Table 2 Correlation analysis between the abundance of archaeal 16S rRNA gene and the environmental variables

\begin{tabular}{llllllllllll}
\hline & $\mathrm{NH}_{4}{ }^{+}$ & $\mathrm{NO}_{3}{ }^{-}$ & $\mathrm{OM}$ & $\mathrm{TN}$ & $\mathrm{TC}$ & $\mathrm{TS}$ & $\mathrm{Fe}^{2+}$ & $\mathrm{Fe}^{3+}$ & $\mathrm{Moisture} \mathrm{content}^{2+} \mathrm{AFT}^{\mathrm{a}}$ & $\mathrm{pH}$ \\
\hline \multicolumn{2}{c}{ Abundance $(n=12)$} & & & & & & & & & \\
$r \quad$ & $0.814 * *$ & 0.155 & $0.865^{* *}$ & -0.227 & -0.093 & -0.040 & 0.829 & -0.415 & $0.724 * *$ & $0.833^{* *}$ & 0.456 \\
Sig. & 0.001 & 0.631 & 0.000 & 0.479 & 0.774 & 0.902 & 0.001 & 0.142 & 0.008 & 0.001 & 0.137 \\
\hline
\end{tabular}

AFT accumulated flooding time (days)

Significance (two tailed); $* * P<0.01$

${ }^{\mathrm{a}}$ The AFT was the flooding duration (days) from the day of the lowest water level in 2013 to the sampling time

Good's coverage of the 16S rRNA gene ranged from 99.7 to $99.9 \%$ indicating that the sequencing effort covered a significant amount of the richness in the examined samples (Fig. S3, Electronic Supplementary Material). The OTU numbers varied from 307 to 837 before water flooding in 2013. Less OTUs were obtained after flooding in 2014 ranging from 175 to 465 . The highest OTU number was observed in the dry sample of 170-2013 before water flooding, accompanied by the highest archaeal richness suggested by the ACE estimation (891), Chao 1 richness estimation (892), and the highest archaeal diversity suggested by the Simpson (0.0531) and Shannon index (4.35). The highest archaeal richness and diversity in 2014 were also observed in dry sample (175-2014) with ACE estimation of 576, Chao 1 richness estimation of 563, Simpson index of 0.1051, and Shannon index of 2.95.

\subsection{Archaeal community structures}

The community structure was compared by PCA based on the Euclidean distance (Fig. 3 and Fig. S4, Electronic Supplementary Material). The wet samples of 155-2013 and 152-2014 at the lowest detected elevations were clustered together. The dry samples of 170-2013, 175-2013, 161-2014, and 175-2014 fell into another cluster. Meanwhile, the wet samples of 165-2013 and 160-2014 which represented the nearest sites to the water level distributed distantly into a separate cluster.

The relative abundances at phylum level showed that the sequences were grouped mainly into two phyla, Thaumarchaeota and Euryarchaeota (Fig. 4). The remaining phylotypes were identified either as Archaea_unclassified group or as others (including Crenarchaeota). Euryarchaeota represented the dominated phylum (77.9 and $95.6 \%$ ) at the lowest elevation sites (155-2013 and 152-2014). Thaumarchaeota was the dominant phylum (92.4 and 89.6\%) at the highest elevation (175-2013 and 175-2014). The Archaea_unclassified group was mostly observed in the dry sample of 170-2013 comprising $30.6 \%$ of the library. The distribution showed that the dominant phylum related to the elevation at the sampling area.

The community structures were then analyzed at deeper taxonomic levels (Fig. 5). A total of 58 taxons were identified and the proportion of each taxon varied significantly in different samples. The highest number of taxons was observed in the wet samples of 155-2013 (48 taxons) and 152-2014 (49 taxons), respectively, whereas the taxon number was only 21 in 165-2013. As less as 26 taxons were observed in 160-2014 and 175-2014 after water flooding. The Soil Crenarchaeotic Group (SCG) which belonged to the phylum of Thaumarchaeota dominated in the samples 165-2013 (48.3\%), 170-2013

Table 3 Diversity and richness indices of samples based on $97 \%$ OTU clusters

\begin{tabular}{|c|c|c|c|c|c|c|c|c|}
\hline Sample ID & Sample type & Reads & OTU & ACE estimation & Chao 1 richness estimation & Good's coverage (\%) & Shannon index & Simpson index \\
\hline $175-2013^{\mathrm{a}}$ & Dry & 43166 & 440 & 591 & 561 & 99.7 & 2.47 & 0.1914 \\
\hline $170-2013^{\mathrm{c}}$ & Dry & 34373 & 837 & 891 & 892 & 99.7 & 4.35 & 0.0531 \\
\hline $165-2013^{\mathrm{c}}$ & Wet & 55042 & 404 & 466 & 450 & 99.8 & 2.35 & 0.2014 \\
\hline $155-2013^{b}$ & Wet & 46030 & 307 & 362 & 348 & 99.9 & 2.50 & 0.2714 \\
\hline $175-2014^{a}$ & Dry & 43117 & 465 & 576 & 563 & 99.7 & 2.95 & 0.1051 \\
\hline $161-2014^{\mathrm{c}}$ & Dry & 38402 & 215 & 275 & 267 & 99.8 & 2.46 & 0.1542 \\
\hline $160-2014^{\mathrm{c}}$ & Wet & 44663 & 175 & 421 & 272 & 99.8 & 2.03 & 0.2109 \\
\hline $152-2014^{b}$ & Wet & 44027 & 383 & 457 & 436 & 99.8 & 2.45 & 0.2470 \\
\hline
\end{tabular}

${ }^{\text {a }}$ Samples of the highest elevation

${ }^{\mathrm{b}}$ Samples of the lowest elevation

${ }^{\mathrm{c}}$ Transition samples, recently flooded (165-2013), soon to be flooded (170-2013), exposed recently (161-2014), and soon to be exposed (160-2014) 


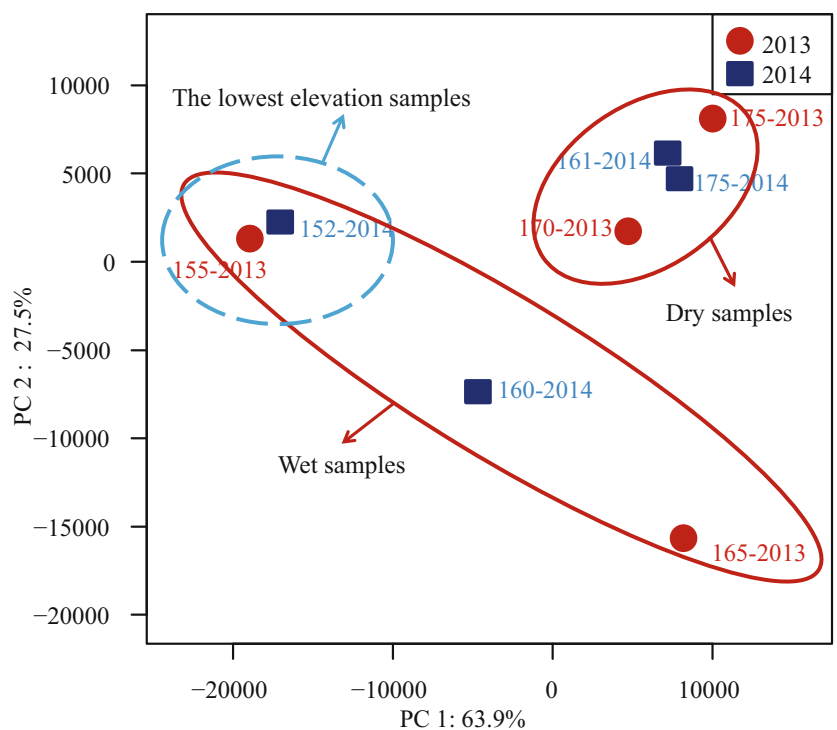

Fig. 3 Principal component analysis (PCA) based on the Euclidean distance matrix between samples. Percentages of the variation explained by each axis were indicated on the figure. Red points and blue rectangles represented the samples collected in 2013 and 2014, respectively

(34.9\%), 175-2013 (71.7\%), 161-2014 (60.5\%), and 175-2014 (65.3\%) after water flooding. In the SCGdominated samples, large proportions of the Candidatus Nitrososphaera were also observed ranging from 15.2 to $39.6 \%$. Nevertheless, at the lowest elevations (samples 155-2013 and 152-2014), the Candidatus Nitrososphaera accounted for only $1.9 \%$ and $0.1 \%$. Additionally, the highest proportions of the Candidatus Nitrososphaera (39.6\% in $165-2013$ and $27.7 \%$ in $160-2014)$ were observed in the wet samples near the water level. Compared with the SCG which dominated in most of the dry samples taken at higher elevations, the Methanosarcina dominated in the wet samples 155-2013 (52.4\%) and 152$2014(49.4 \%)$ taken at the lowest elevation. A relative even distribution was observed in sample 160-2014 with the SCG $33.4 \%$, Candidatus Nitrososphaera $27.7 \%$, and Methanosarcina $33.1 \%$.

\subsection{Community composition and environmental variables}

RDA was performed to evaluate the relationship between the community composition and environmental variables (Fig. 6). Forward-selected environmental variables (moisture content, $\mathrm{NH}_{4}{ }^{+}, \mathrm{Fe}^{2+}$, and sampling elevations) were employed as $P<0.05$ in the selection procedure by Monte Carlo permutation test. RDA 1 and RDA 2 explained 61.5 and $29.5 \%$ of the total variation, respectively.

Groups with more than $1.0 \%$ of the trimmed sequences including SCG (41.8\%), Candidatus Nitrososphaera (18.9\%), Methanosarcina (18.7\%), unclassified Archaea (4.1\%), Methanobacterium (3.6 \%), unclassified Euryarchaeota (1.9\%), Methanoregula (1.8\%), GOM Arc I (1.5\%), Miscellaneous Crenarchaeotic group (1.2\%), and Deep Sea Hydrothermal Vent Gp 6 (DHVEG-6) (1.1\%) were selected for RDA. The SCG and Candidatus Nitrososphaera affiliated with the thaumarchaeotal AOA group (labeled in green) were positively correlated with the variable "elevation," but negatively correlated with the $\mathrm{Fe}^{2+}, \mathrm{NH}_{4}^{+}$, and moisture content. In contrast, the euryarchaeotal methanogenic members (labeled in blue) Methanosarcina, Methanobacterium, Methanoregula, and GOM Ar I showed positive correlations with the $\mathrm{Fe}^{2+}, \mathrm{NH}_{4}{ }^{+}$, and moisture content. Overall, the archaeal community structures were more likely to be regulated by the moisture and elevation gradients (Fig. 6).

\section{Discussion}

The response of archaeal community to the periodic water flooding was investigated in the WLFZ of the TGR. Our study showed that the archaeal abundance, diversity, and community composition were clearly affected by the fluctuation of water level.
Fig. 4 Relative abundance of the dominant archaeal phylum in different samples. Sampling year and elevation were indicated in the name of sample. Light yellow and light blue indicated the samples in dry or wet conditions, respectively. The phylogenetic groups accounting for $<1 \%$ of all quality sequences were summarized in the artificial group as "Others". Multi-colored charts at the legend were shown for each phylum correspondingly

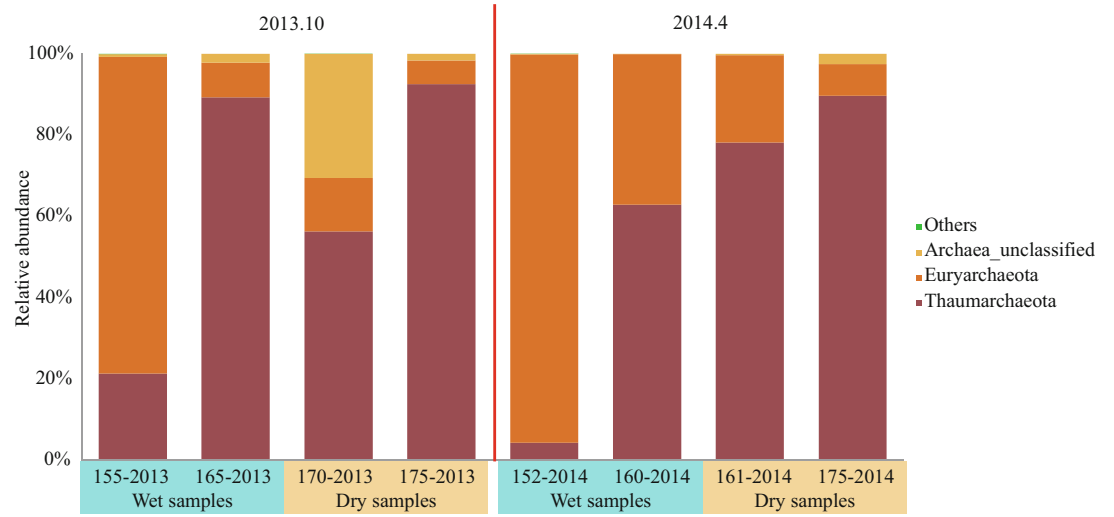




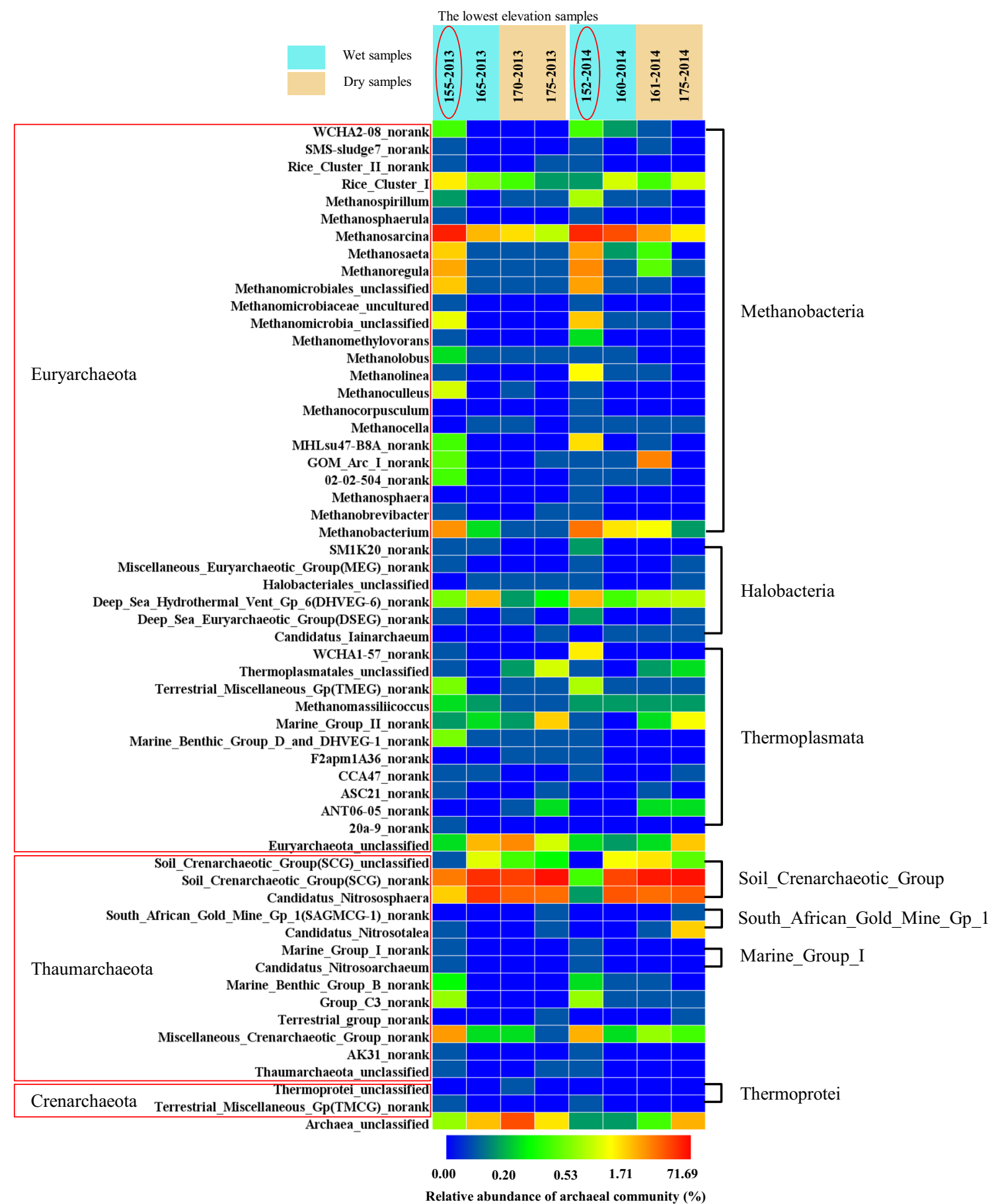

Fig. 5 Heatmap generated with software HemI version 1.0 of the archaeal community composition in different samples. Heatmap colors represented the relative abundance of the OTUs in the samples, as indicated by the color legend. The affiliations of OTUs were clustered in different phylogenetic level. Red boxes and black square brackets were

\subsection{Increase of archaeal abundance after water flooding}

The archaeal abundance of wet samples was comparable with the reported abundances in similar habitats like pond sediments (Brandt et al. 2014), rich fen (Petersen et al. 2012), used to group OTUs into phyla and classes, respectively. Light yellow and light blue indicated the samples in dry or wet conditions, respectively. Samples 155-2013 and 152-2014 as the lowest elevation samples were circled in red

and estuarine sediments (Webster et al. 2015). By contrast, those of the dry samples $\left(1.4 \times 10^{8}\right.$ to $2.4 \times 10^{9}$ copies $(\mathrm{g}$ d.w.s. $)^{-1}$ ), which underwent periodic flooding, were $1-2$ orders of magnitude higher than most of the abundance reported in soil habitats, such as soil in China $\left(5.0 \times 10^{6}\right.$ to $1.3 \times 10^{8}$ 
Fig. 6 The redundancy analyses (RDA) of the community composition and environmental variables. Environmental variables and groups of archaea are indicated by arrows and triangles, respectively

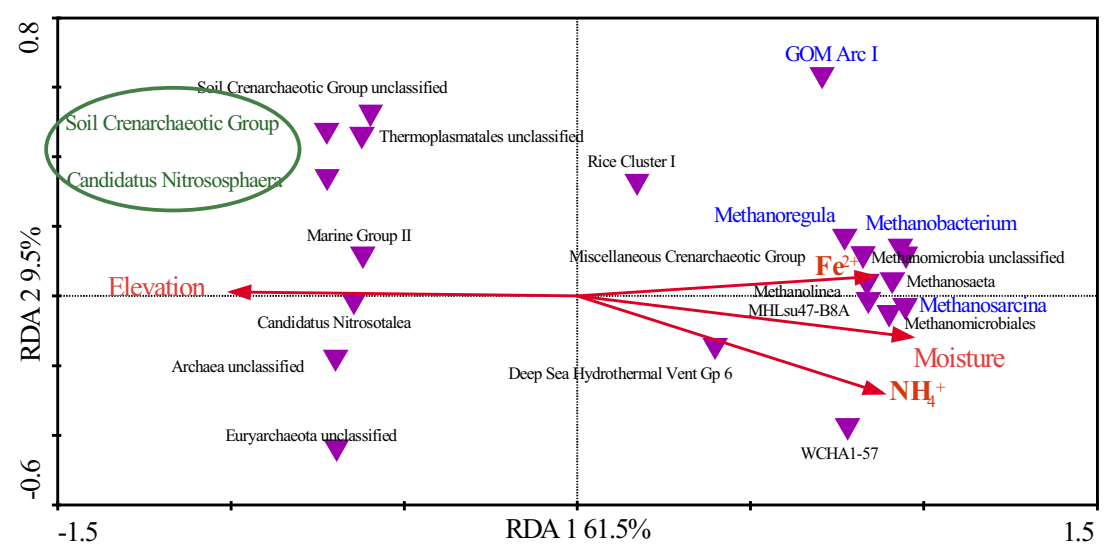

copies $\mathrm{g}^{-1}$ dry soil) (Cao et al. 2012), tropical soil in Malaysia (about $1.0 \times 10^{7}$ to $1.4 \times 10^{8}$ copies $\mathrm{g}^{-1}$ soil) (Tripathi et al. 2013), and beech forest soil in Austria $\left(6.1 \times 10^{7}\right.$ copies $g^{-1}$ soil) (Rasche et al. 2011). In addition to the higher archaeal abundance observed in wet samples, the average abundance of all samples increased from $3.8 \times 10^{8}$ to $3.8 \times 10^{9}$ copies (g d.w.s.) $)^{-1}$ after water flooding in 2014 . The positive effect of flooding to the archaeal abundance was associated with the soil moisture content, implied by the correlation analysis $(P<0.01)$. Previous studies have revealed that higher archaeal abundance was observed when soil moisture increased (Rasche et al. 2011; Tian et al. 2012). It is very likely that the high soil water content led to more strictly anaerobic conditions, which promoted the growth of methanogens group of archaea (Tian et al. 2012). Additionally, the high level of inorganic nitrogen and organic carbon induced by the increasing water content (Tian et al. 2012; Macrae et al. 2013) would be an incentive to the archaeal population by providing them substrates for living (Liu et al. 2011). It was also confirmed by the positive correlation between the archaeal abundance and the $\mathrm{NH}_{4}{ }^{+}$and $\mathrm{OM}(P<0.01)$ (Table 2$)$ in this study.

\subsection{Archaeal diversity related to water flooding}

Despite the low abundance of archaea, relatively higher archaeal diversities were observed in the dry samples at higher elevations. Compared with the saturated water content in flooded wet samples, the presence of the soil moisture gradient and unfilled pores in the dry samples usually led to a heterogeneous environments with both anaerobic and aerobic micro niches (Puertolas et al. 2013), which would support higher microbial diversities (Walsh et al. 2005; Crump et al. 2012). As a carrier of nutrients, the soil water also regulates the soil nutrients (Bao et al. 2015), which were considered to be the best predictors of microbial diversity (Nielsen et al. 2010; Wessén et al. 2010). Therefore, the inhomogeneous soil water condition in the dry samples might be a key factor for the higher diversity of archaea.

\subsection{Archaeal community composition along the elevation}

The patterns of archaeal community composition closely related to the sampling elevations. Thaumarchaeota was the dominant phylum in the dry samples at higher elevations (56.3-92.4 \% in 2013, 78.1-89.6\% in 2014). This was in agreement with the findings that Thaumarchaeota inhabited in soil with considerable amount (Pester et al. 2011; Stieglmeier et al. 2014). The relative low proportion of Thaumarchaeota in wet samples, which was identified to be more adaptive into oligotrophic habitat (Reitschuler et al. 2016), was probably associated with the high content of $\mathrm{NH}_{4}^{+}$, as shown in Fig. 6 (RDA). Within the phylum of Thaumarchaeota, the thaumarchaeotal SCG was dominant in dry samples (Figs. 4 and 5), indicating the importance of ammonia oxidation of archaea in dry soils (Breidenbach et al. 2015). Interestingly, the highest proportions of the Candidatus Nitrososphaera, which was another essential group in Thaumarchaeota, were observed in wet samples near the water level (39.6\% in 165-2013 and $27.7 \%$ in 160-2014). The distribution of Candidatus Nitrososphaera might be caused by the presence of organic matter. Organic matter was usually enriched from vegetation decomposition and terrestrial input in the transition zone (Chao et al. 2011). A previous study by Bouali et al. showed a better performance of the Candidatus Nitrososphaera in an organic-rich habitat (Bouali et al. 2012). Moreover, the fluctuating water levels could create microaerobic niches providing a suitable environment at the transition area for aerobic ammonia-oxidizing archaeon of the Candidatus Nitrososphaera (Breidenbach et al. 2015). The respective distribution of thaumarchaeotal SCG and Candidatus Nitrososphaera implied their subtle difference in habitat adaption.

Unlike the high proportion of Thaumarchaeota in dry soil, the phylum Euryarchaeota dominated in the lowest sites (155-2013 and 152-2014) covering 78.0 and $96.0 \%$ of the retrieved sequences. It was identified that most of the Euryarchaeota were strict anaerobes (e.g., methanogens) and were positively correlated with 
moisture content in soil (Hu et al. 2013). Besides, stable redox habitats were also favorable of Euryarchaeota (Hugoni et al. 2015). In the WLFZ of TGR, the longer flooding time in lower sites created relative stable and anaerobic environments which were suitable for Euryarchaeota and resulted in a high proportion of Euryarchaeota. The euryarchaeotal Methanosarcina was the most abundant methanogen in this study, covering 52.4 and $49.4 \%$ of the retrieved sequences in wet samples of 155-2013 and 152-2014, respectively. Nevertheless, the proportions of the Methanosarcina, Methanobacterium, Methanoregula, and GOM Arc I decreased dramatically in higher elevations (Fig. 5). The distribution of methanogens along the elevation gradients was in agreement with their strict anaerobic metabolism (Deng et al. 2014b), which was also identified by the RDA (Fig. 6). Water flooding was a direct approach to produce anaerobic condition in soil, which explained methanogens were only abundant in frequently or permanently flooded soils (Kemnitz et al. 2004; Høj et al. 2006). The population of methanogenic archaea, which was supposed to be an incentive of methane emission, increased when the water level rose. However, in the meantime, the anaerobic habitat may also stimulate anaerobic methane oxidation in the TGR (Wang et al. 2014). Therefore, the formation of WLFZ does not necessarily enhance the methane emission when the water rises (Bodelier et al. 2012).

Until recently, the freshwater-based archaea community was debated as being habitat (e.g., soil, sediment, marine, freshwater) specific or location specific (Newton et al. 2011; Silveira et al. 2013). The conclusion of habitat specificity seems more plausible in the WLFZ. A distinct archaeal abundance, community composition, and diversity were identified in wet and dry soils. Therefore, the archaea, in contrast to the more heterogeneous and unsteady bacterial and fungal community (Reitschuler et al. 2016), could potentially function as an ecological indicator of the dam's environmental influence.

\section{Conclusions}

The results in this study provide fundamental insights into the archaeal community structure responding to water flooding. The abundance, diversity, and community composition of archaea were clearly influenced by the water fluctuating along the elevation gradient. An increase of abundance after water flooding and elevation related community composition and diversity were recorded in this WLFZ for the first time. The water flooding could be the key dynamic environmental factor influencing the archaeal community in the WLFZ. This comprehensive analysis will also enhance the overall understanding of the microbial ecology in the WLFZ of the TGR.
Acknowledgments This work was supported by the National Natural Science Foundation of China [41303053, 31300025, 41401051], Fundamental and Frontier Research Project of Chongqing [cstc2013jcyjA20003], and West Light Foundation and West China Action Plan of the Chinese Academy of Sciences [KZCX2-XB3-14-01]

\section{References}

Angel R, Soares MIM, Ungar ED, Gillor O (2010) Biogeography of soil archaea and bacteria along a steep precipitation gradient. ISME J 4: 553-563

Antheunisse AM, Loeb R, Miletto M, Lamers LP, Laanbroek HJ, Verhoeven JT (2007) Response of nitrogen dynamics in seminatural and agricultural grassland soils to experimental variation in tide and salinity. Plant Soil 292:45-61

Bao S (2000) Chemical analysis for agricultural soil. China Agriculture Press, Beijing

Bao YH, Gao P, He XB (2015) The water-level fluctuation zone of Three Gorges Reservoir - a unique geomorphological unit. Earth-Sci Rev 150:14-24

Bates ST, Berg-Lyons D, Caporaso JG, Walters WA, Knight R, Fierer N (2011) Examining the global distribution of dominant archaeal populations in soil. ISME J 5:908-917

Bodelier PL, Bar-Gilissen MJ, Meima-Franke M, Hordijk K (2012) Structural and functional response of methane-consuming microbial communities to different flooding regimes in riparian soils. Ecol Evol 2:106-127

Bouali M, Zrafi-Nouira I, Bakhrouf A, Le Paslier D, Chaussonnerie S, Ammar E, Sghir A (2012) The structure and spatio-temporal distribution of the archaea in a horizontal subsurface flow constructed wetland. Sci Total Environ 435:465-471

Braker G, Ayala-del-Río HL, Devol AH, Fesefeldt A, Tiedje JM (2001) Community structure of denitrifiers, bacteria, and archaea along redox gradients in Pacific Northwest marine sediments by terminal restriction fragment length polymorphism analysis of amplified nitrite reductase (nirS) and 16S rRNA genes. Appl Environ Microbiol 67:1893-1901

Brandt FB, Breidenbach B, Brenzinger K, Conrad R (2014) Impact of short-term storage temperature on determination of microbial community composition and abundance in aerated forest soil and anoxic pond sediment samples. Syst Appl Microbiol 37:570-577

Breidenbach B, Blaser MB, Klose M, Conrad R (2015) Crop rotation of flooded rice with upland maize impacts the resident and active methanogenic microbial community. Environ Microbiol. doi:10.1111 /1462-2920.13041

Burggraf S, Huber H, Stetter KO (1997) Reclassification of the crenarchael orders and families in accordance with 16S rRNA sequence data. Int J Syst Bacteriol 47:657-660

Cao P, Zhang L, Shen J, Zheng Y, Di HJ, He J (2012) Distribution and diversity of archaeal communities in selected Chinese soils. FEMS Microbiol Ecol 80:146-158

Chao C, Zongqiang X, Gaoming X, Limin C (2011) The effect of flooding on soil physical and chemical properties of riparian zone in the Three Gorges Reservoir. J Nat Res 26:1236-1244

Chen H, Yuan X, Gao Y, Wu N, Zhu D, Wang J (2010) Nitrous oxide emissions from newly created littoral marshes in the drawdown area of the Three Gorges Reservoir, China. Water Air Soil Pollut 211:25-33

China Three Gorges Corporation (2015) Introduction of Three Gorges Corporation (in Chinese). Publisher. http://www.ctg.com. $\mathrm{cn} /$ sxgc/newsdetail2.php

Crump BC, Amaral-Zettler LA, Kling GW (2012) Microbial diversity in arctic freshwaters is structured by inoculation of microbes from soils. ISME J 6:1629-1639 
DeAngelis KM, Silver WL, Thompson AW, Firestone MK (2010) Microbial communities acclimate to recurring changes in soil redox potential status. Environ Microbiol 12:3137-3149

Delong EF (1992) Archaea in coastal marine environments. Proc Natl Acad Sci U S A 89:5685-5689

Deng W, Wang Y, Liu Z, Cheng H, Xue Y (2014a) HemI: a toolkit for illustrating heatmaps. PLoS One 9:e111988

Deng Y, Cui X, Hernández M, Dumont MG (2014b) Microbial diversity in hummock and hollow soils of three wetlands on the QinghaiTibetan Plateau revealed by $16 \mathrm{~S}$ rRNA pyrosequencing. PLoS One 7:e103115

Fuhrman JA, McCallum K, Davis AA (1992) Novel major archaebacterial group from marine plankton. Nature 356:148-149

Gro kR, Stubner S, Liesack W (1998) Novel euryarchaeotal lineages detected on rice roots and in the anoxic bulk soil of flooded rice microcosms. Appl Environ Microbiol 64:4983-4989

Guodong Z, Takano B, Kuno A, Matsuo M (2001) Iron speciation in modern sediment from Erhai Lake, southwestern China. Redox conditions in an ancient environment. Appl Geochem 16:1201-1213

Høj L, Rusten M, Haugen LE, Olsen RA, Torsvik VL (2006) Effects of water regime on archaeal community composition in Arctic soils. Environ Microbiol 8:984-996

Hu H, Zhang L, Yuan C, He J (2013) Contrasting Euryarchaeota communities between upland and paddy soils exhibited similar $\mathrm{pH}$-impacted biogeographic patterns. Soil Biol Biochem 64: $18-27$

Hugoni M, Domaizon I, Taib N, Biderre-Petit C, Agogué H, Galand PE, Debroas D, Mary I (2015) Temporal dynamics of active archaea in oxygen-depleted zones of two deep lakes. Environ Microbiol Rep 7: 321-329

Jin T, Zhang T, Ye L, Lee OO, Wong YH, Qian PY (2011) Diversity and quantity of ammonia-oxidizing archaea and bacteria in sediment of the Pearl River Estuary, China. Appl Microbiol Biotechnol 90: $1137-1145$

Kemnitz D, Chin KJ, Bodelier P, Conrad R (2004) Community analysis of methanogenic archaea within a riparian flooding gradient. Environ Microbiol 6:449-461

Könneke M, Bernhard AE, José R, Walker CB, Waterbury JB, Stahl DA (2005) Isolation of an autotrophic ammonia-oxidizing marine archaeon. Nature 437:543-546

Leininger S, Urich T, Schloter M, Schwark L, Qi J, Nicol G, Prosser J, Schuster S, Schleper C (2006) Archaea predominate among ammonia-oxidizing prokaryotes in soils. Nature 442:806-809

Liu D, Ding W, Jia Z, Cai Z (2011) Relation between methanogenic archaea and methane production potential in selected natural wetland ecosystems across China. Biogeosciences 8:329-338

Liu J, Yu S, Zhao M, He B, Zhang X (2014) Shifts in archaeaplankton community structure along ecological gradients of Pearl Estuary. FEMS Microbiol Ecol 90:424-435

Macrae M, Devito K, Strack M, Waddington J (2013) Effect of water table drawdown on peatland nutrient dynamics: implications for climate change. Biogeochemistry 112:661-676

Newton RJ, Jones SE, Eiler A, Mcmahon KD, Bertilsson S (2011) A guide to the natural history of freshwater lake bacteria. Microbiol Mol Biol Rev 75:14-49

Nielsen UN, Osler GH, Campbell CD, Burslem DF, van der Wal R (2010) The influence of vegetation type, soil properties and precipitation on the composition of soil mite and microbial communities at the landscape scale. J Biogeogr 37:1317-1328

Offre P, Spang A, Schleper C (2013) Archaea in biogeochemical cycles. Annu Rev Microbiol 67:437-457

Pester M, Schleper C, Wagner M (2011) The Thaumarchaeota: an emerging view of their phylogeny and ecophysiology. Curr Opin Microbiol 14:300-306

Petersen DG, Blazewicz SJ, Firestone M, Herman DJ, Turetsky M, Waldrop M (2012) Abundance of microbial genes associated with nitrogen cycling as indices of biogeochemical process rates across a vegetation gradient in Alaska. Environ Microbiol 14:993-1008

Puertolas J, Alcobendas R, Alarcón JJ, Dodd IC (2013) Long-distance abscisic acid signalling under different vertical soil moisture gradients depends on bulk root water potential and average soil water content in the root zone. Plant Cell Environ 36: $1465-1475$

Qiu J (2009) Chinese dam may be a methane menace: wetlands around Three Gorges produce tonnes of the greenhouse gas. Nature. doi:10.1038/news.2009.962

Rasche F, Knapp D, Kaiser C, Koranda M, Kitzler B, ZechmeisterBoltenstern S, Richter A, Sessitsch A (2011) Seasonality and resource availability control bacterial and archaeal communities in soils of a temperate beech forest. ISME J 5:389-402

Reitschuler C, Hofmann K, Illmer P (2016) Abundances, diversity and seasonality of (non-extremophilic) archaea in Alpine freshwaters. Anton Leeuw Int J G 109:855-868. doi:10.1007/s10482-016-0685-6

Silveira CB, Cardoso AM, Coutinho FH, Lima JL, Pinto LH, Albano RM, Clementino MM, Martins OB, Vieira RP (2013) Tropical aquatic archaea show environment-specific community composition. PLoS One 8:e76321

Smeulders MJ, Barends TR, Pol A, Scherer A, Zandvoort MH, Udvarhelyi A, Khadem AF, Menzel A, Hermans J, Shoeman RL (2011) Evolution of a new enzyme for carbon disulphide conversion by an acidothermophilic archaeon. Nature 478:412-416

Stieglmeier M, Alves RJ, Schleper C (2014) The Phylum Thaumarchaeota. In: The Prokaryotes. Springer, Berlin, Heidelberg, pp 347-362

Stone R (2008) China's environmental challenges: Three Gorges Dam: into the unknown. Science 321:628-632

Sun ZG, Zhang L, Duan ZD (2013) The quantity and distribution of reservoir engineering in China. China Water Resour 7:10-11

Tian J, Zhu Y, Kang X, Dong X, Li W, Chen H, Wang Y (2012) Effects of drought on the archaeal community in soil of the Zoige wetlands of the Qinghai-Tibetan plateau. Eur J Soil Biol 52:84-90

Tripathi BM, Kim M, Lai-Hoe A, Shukor NA, Rahim RA, Go R, Adams JM (2013) pH dominates variation in tropical soil archaeal diversity and community structure. FEMS Microbiol Ecol 86:303-311

Walsh DA, Papke RT, Doolittle WF (2005) Archaeal diversity along a soil salinity gradient prone to disturbance. Environ Microbiol 7:1655-1666

Wang C, Xiao S, Li Y, Zhong H, Li X, Feng P (2014) Methane formation and consumption processes in Xiangxi Bay of the Three Gorges Reservoir. Sci Rep 4:4449-4449

Webster G, O'Sullivan LA, Meng Y, Williams AS, Sass AM, Watkins AJ, Parkes RJ, Weightman AJ (2015) Archaeal community diversity and abundance changes along a natural salinity gradient in estuarine sediments. FEMS Microbiol Ecol 91:1-18

Wemheuer B, Wemheuer F, Daniel R (2012) RNA-based assessment of diversity and composition of active archaeal communities in the German Bight. Archaea 2012:425-431

Wessén E, Hallin S, Philippot L (2010) Differential responses of bacterial and archaeal groups at high taxonomical ranks to soil management. Soil Biol Biochem 42:1759-1765

Whitman WB, Bowen TL, Boone DR (2006) The methanogenic bacteria. In: The Prokaryotes. Springer, Berlin, Heidelberg, pp 165-207

Wuchter C, Abbas B, Coolen MJ, Herfort L, van Bleijswijk J, Timmers P, Strous M, Teira E, Herndl GJ, Middelburg JJ (2006) Archaeal nitrification in the ocean. P Natl Acad Sci USA 103:12317-12322

Xu X, Tan Y, Yang G (2013) Environmental impact assessments of the Three Gorges Project in China: issues and interventions. Earth-Sci Rev 124:115-125

Ye C, Cheng X, Zhang Y, Wang Z, Zhang Q (2012) Soil nitrogen dynamics following short-term revegetation in the water level fluctuation zone of the Three Gorges Reservoir, China. Ecol Eng 38:37-44

Ye C, Li SY, Yang YY, Shu X, Zhang JQ, Zhang QF (2015) Advancing analysis of spatio-temporal variations of soil nutrients in the water 
level fluctuation zone of China's Three Gorges Reservoir using selforganizing map. PLoS One 10:e0121210

Yuan WH, Yin DW, Finlayson B, Chen ZY (2012) Assessing the potential for change in the middle Yangtze River channel following impoundment of the Three Gorges Dam. Geomorphology 147-148: $27-34$
Zhang L, Wang M, Prosser JI, Zheng Y, He J (2009) Altitude ammoniaoxidizing bacteria and archaea in soils of Mount Everest. FEMS Microbiol Ecol 70:208-217

Zhou L, Wang Y, Long XE, Guo J, Zhu G (2014) High abundance and diversity of nitrite-dependent anaerobic methane-oxidizing bacteria in a paddy field profile. FEMS Microbiol Lett 360:33-41 